\title{
Methanolic Extract of Asterina pectinifera inhibits LPS-Induced Inflammatory Mediators in Murine Macrophage
}

\author{
Wol-Soon Jo', Yoo Jin Choi', Hyoun Ji Kim', Byung Hyouk Nam², Gye An Lee', \\ Su Yeong Seo', Sang Wha Lee' and Min Ho Jeong' \\ ${ }^{1}$ Department of Microbiology, Dong-A University College of Medicine, Busan 602-714 \\ ${ }^{2}$ Deartment of Microbiology, College of Natural Sciences, Pusan National University, Busan 609-735 \\ ${ }^{3}$ NLP Co. LTD, Busan 619-912, Korea
}

(Received February 17, 2010; Revised February 18, 2010; Accepted February 26, 2010)

\begin{abstract}
This study aimed to elucidate anti-inflammatory activities from extracts of Asterina pectinifera on nitric oxide (NO) production, TNF- $\alpha$ and IL-6 release in lipopolysaccharide (LPS)-stimulated murine macrophage cell, RAW264.7. We prepared the methanolic extracts (60-MAP, 70-MAP, 80-MAP and 90-MAP), aqueous extract (W-AP) and functional bioactive compound fraction (He-AP and EA-AP) from Asterina pectinifera according to extract method. The 60-MAP, 70-MAP, 80-MAP, 90-MAP and W-AP were significantly suppressed LPS-induced production NO, TNF- $\alpha$ and IL-6 secretion in a concentration-dependent manner $(P<0.05)$. Especially, 80 -MAP by extracted $80 \%$ methanol had the strongest activity in reduction of inflammatory mediators among these extracts. Indeed, to identify active fraction, which contained potential bioactive compounds, from 80-MAP of Asterina pectinifera, we tested anti-inflammatory activity of the He-AP or the EA-AP. The He-AP was next extracted from 80-MAP and the EA-AP were extracted from the other methanol layer except the He-AP. The EA-AP demonstrated a strong anti-inflammatory effect through its ability to reduce NO production and it also inhibited the production of proinflammatory cytokines such as IL- 6 and TNF- $\alpha$ at low concentration. These results suggested that the methanolic extract from Asterina pectinifera had the potential inhibitory effects on the production of these inflammatory mediators.
\end{abstract}

Key words: Asterina pectinifera, Methanolic extract, Aqueous extract, LPS, RAW 264.7 cell, Antiinflammatory activity, Nitric oxide, Pro-inflammatory cytokines

\section{INTRODUCTION}

Inflammation is a pathophysiological response of mammalian tissues to a variety of hostile agents including infectious organisms, toxic chemical substances, physical injury or tumor growth leading to local accumulation of plasmic fluid and blood cells (Sobota et al., 2000). Prolonged inflammation contributes to the pathogenesis of many inflammatory diseases, including bronchitis (Vernooy et al., 2002), gastritis (Sakagami et al., 1997), inflammatory bowel disease (IBD) (Fichtner-Feigl et al., 2005; Ishiguro, 1999), multiple sclerosis (MS) (Klotz et al., 2005), and rheumatoid arthritis (RA) (Walsh et al., 2005). Although inflammation is a defense mechanism, the complex events and

Correspondence to: Min-Ho Jeong, Department of Microbiology, Dong-A University College of Medicine, Dongdaesindong, Seo-gu, Busan 602-714, Korea

E-mail: mhjeong@dau.ac.kr mediators involved in the inflammatory reaction can induce, maintain and aggravate many physiologic disorders.

Macrophages play an important role in the regulation of inflammation and the immune response by releasing inflammatory mediators such as pro-inflammatory cytokines (TNF- $\alpha$, IL-1 $\beta$ and IL-6), nitric oxide (NO) and prostaglandin E2 (PGE2), that recruit additional immune cells to sites of infection or tissue injury (Boscá et al., 2005). Following exposure to immune stimulants, including bacterial toxins, such as lipopolysaccharide (LPS) and lipoteichoic acid, the production of these mediators from macrophages has been found in many inflammatory tissue along with the increased expressions of their mRNAs (Penglis et al., 2000). Nitric oxide (NO), prostaglandin E2 (PGE2) and the cytokines, such as interleukin-1 beta (IL-1 $\beta$ ), IL-6 and tumor necrosis factor- $\alpha$ (TNF- $\alpha)$, are well known for their involvement in the development of inflammation (Sautebin, 2000). Although $\mathrm{NO}$ and pro-inflammatory cytokines are involved in the host defense mechanism, their overproduction contributes 
to the pathogenesis of several diseases, such as sepsis, rheumatoid arthritis, atherosclerosis, pulmonary fibrosis and chronic hepatitis (Coker and Laurent, 1998). Hence, the employment of anti-inflammatory agents may be helpful in the therapeutic treatment of those pathologies associated with inflammatory reactions (Sosa et al., 2002). The clinical treatment of inflammatory diseases is dependent on drugs which belong either to the non-steroidal or steroidal chemical therapeutics. The nonsteroidal anti-inflammatory drugs (NSAIDs) such as aspirin, indomethacin and ibuprofen inhibit early steps in the biosynthesis pathway of prostaglandins by inhibition of COX enzymes and are the main drugs used to reduce the untoward consequences of inflammation. However, the side effects of the currently available anti-inflammatory drugs pose a major problem in their clinical use (Albert et al., 2002). Indeed, a need arises for the development of newer anti-inflammatory agents from natural sources with more powerful activity and with lesser side effects as substitutes for chemical therapeutics.

Starfish among marine organism, natural enemy of fishing farm, has been gradually increasing as fish farm has been enlarging. It is known that starfish has very strong reproduction-power, namely cutting part of the body as well as the whole body can grow up to new individuals. Starfish gives serious damages to useful shellfish, ark shell, abalone, little clam, scallop etc., inhabiting in shellfish farms of coastal area (Park, 1997). Generally, the species of starfish grown in Korea sea, which is known to give serious damage to shellfish farm, known as is Asterias amurensis and Asterina pectinifera (Park and Kim, 1985), and damage of shellfish farm is very serious situation because a lots of starfishes have already been bred in the marine of Korea $(0.5$ starfish per $\mathrm{m}^{2}$ ) (Kang, 2000). Among these starfish, crude extracts of starfish Acanthaster planci, Asterias forbesi, and Asterina pectinifera are active against influenza B virus in embryonated chicks. Seo et al. reported that extracts obtained from Asterina pectinifera have antimicrobial and anticancer activities. Cho et al. (1994) reported that the starfish Asterina pectinifera, one of unused marine resources, exhibits antimicrobial capacities against B. subtilis and $S$. aureus. Also, Cho et al. (2000) separated and identified natural antimicrobial agent, antioxidative agent, anticholesterol agent, and anticoagulant agent from starfish. A protein isolated from the starfish $A$. forbesi was found to cause a delayed inflammatory response in mammalian species and macrophage migration (Prendergast and Suzuki, 1970). It was also reported that $A$. pectinifera also produces polyhydroxysteroids and steroidal saponins like other seastars to deter mobile predators from feeding (Prokof'eva, 2003). Especially, many of these compounds such as marine polyhydroxysteroids and glycosides of polyhydroxysteroids from the starfish were reported to possess anti-inflammatory effects (Choi et al., 1999).

Although many other natural products isolated from star- fish as marine organisms, they have been little known to exert inhibitory effects on a variety of inflammation. Therefore, in this study, we investigated the active fraction which contained potential bioactive compounds from Asterina pectinifera according to extract method such as stepwise solvent extraction or aqueous extract with commercial proteases, Protamex $^{\mathrm{TM}}$, and then measured anti inflammatory acitivities of NO and pro-inflammatory cytokines on lipopolysaccharide (LPS)-stimulated RAW 264.7 cells.

\section{MATERIALS AND METHODS}

Chemicals. RPMI 1640 media and fetal bovine serum (FBS) were purchased from Gibco Ltd. (Grand Island, NY, USA). MTT (3-(4,5-dimethylthiazol-2-yl)-2,5-diphenyl tetrazolium bromide), LPS, L-NMMA ( $\mathrm{N}^{\mathrm{G}}$-Methyl-L-arginine acetate salt), polymyxin $\mathrm{B}$, arachidonic acid and indomethacin were purchased from Sigma Chemicals Co. (St. Louis, MO, USA). TNF- $\alpha$ and IL-6 were obtained from BD science (California, USA) and all other solvents/chemicals were used reagent or analytical grade.

Preparation of Asterina pectinifera. The materials used in this study were starfish, Asterina pectinifera, which are known to give serious damages to shellfish farm. These were obtained from coastal region of Ilgwan-Mun in Gijanggun of Busan from Korea (The depth of water is within about 30 50 m), put into an ice chest and transferred to laboratory (Dept. of microbiology, Dong-A University). After transferring, these materials were cleaned, washed with distilled water, and were air-dried at $40^{\circ} \mathrm{C}$. They were blended with a blender (Waring blender Co., USA), the blended materials were used immediately in an experiment.

Extraction and fraction. The extraction of potentially bioactive compounds followed by a method shown in Fig. 1. For the methanolic extract, the powdered Asterina pectinifera $(100 \mathrm{~g}$ d.w.) were extracted with each concentration $(60,70,80$ and $90 \%)$ of methanol at room temperature and were ultrasonicated (Sonic Dismembrator, Fisher Scientific Inc., USA) for $30 \mathrm{~min}$. The methnolic extracts were filtered by whatman filter paper (Particle retention; 20 25 $\mu \mathrm{m}$ ) and the filtrates were made into powder by vacuum rotary evaporator (Eyela, N-INW, Tokyo Rikakikai Co., Ltd, Japan), at $40^{\circ} \mathrm{C}$ (Fig. 1A). Each methnolic concentration treated samples of of Asterina pectinifera were designated by 60-MAP, 70-MAP, 80-MAP and 90-MAP. In the same way shown above, the sample of optimal condition from methnolic concentrations was added into hexane $\left(n-\mathrm{C}_{6} \mathrm{H}_{14}, 1: 1\right.$ ratio, w/v) and was agitated to extract hexane fraction (He-AP) for $24 \mathrm{~h}$ at room temperature. Then, the hexane fraction was excluded and the other methnolic layer was made into powder by vacuum rotary evaporator (Fig. 1B). The methnolic layer was added ethyl acetate (EtOAc, 2:1 ratio, w/v) 


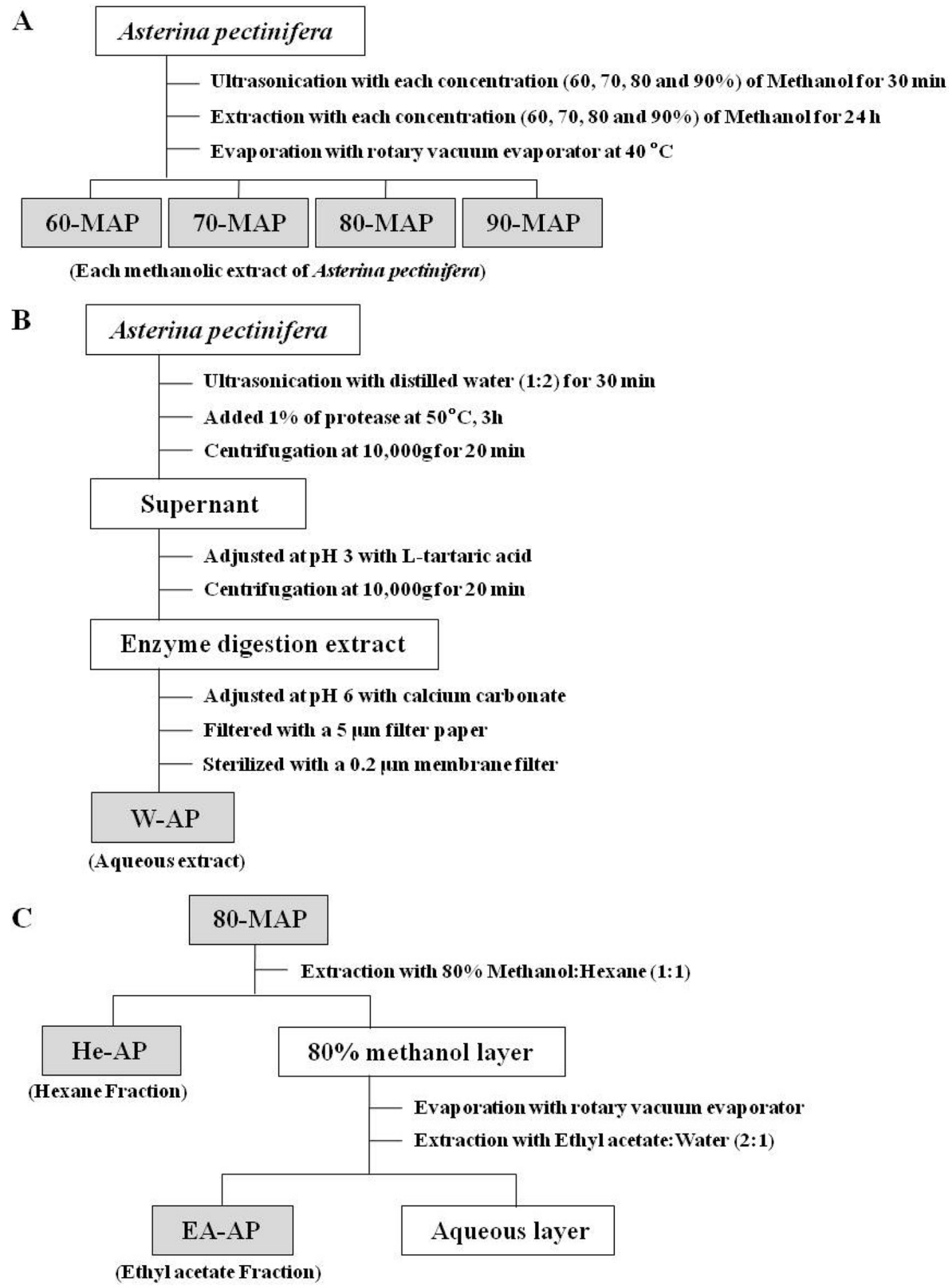

Fig. 1. Procedure for extraction or fraction of bioactive compounds from Asterina pectinifera. The extractive procedures were described in (A) the methnolic extraction, $(B)$ the aqueous extraction and $(C)$ the hexane fraction or ethyl acetate fraction according to extract method from Asterina pectinifera.

again and was agitated to extract ethyl acetate fraction (EAAP) for $24 \mathrm{~h}$ at room temperature. All kinds of the extracts and fractions were concentrated using vacuum rotary evaporator, dissolved in DMSO (Dimethyl sulfoxide, Kento, Japan) and stored in a refrigerator $\left(4^{\circ} \mathrm{C}\right)$ until use.

On the other hand, the other treatment, which added with protease (Protamex ${ }^{\mathrm{TM}}$, Novo Nordisk Co., Denmark), was processed. Namely, dried powder $100 \mathrm{~g}$ of Asterina pectinifera were ultrasonicated with distilled water $(1: 2$ ratio, w/v) for $30 \mathrm{~min}$ and the sample was added $1 \%$ of protease (to dried weight of sample). The enzyme reactant was incubated at $50^{\circ} \mathrm{C}$ for $3 \mathrm{~h}$ and centrifuged at $10,000 \mathrm{~g}$ for $20 \mathrm{~min}$. The supernant was adjusted at $\mathrm{pH} 3$ with L-tartaric acid until the supernant was transparent solution. After centrifugation again at $10,000 \mathrm{~g}$ for $20 \mathrm{~min}$, the supernant was readjusted at $\mathrm{pH} 6$ with calcium carbonate. The sample was filtered with filter paper (Particle retention; $5 \mu \mathrm{m}$ ) and then was filtered with $0.2 \mu \mathrm{m}$ membrane filter (ADVANTEC MFS, Inc., California, USA) again (Fig. 1C). This extract was designated by the aqueous extract (W-AP) of Asterina 
pectinifera and stored in a refrigerator $\left(4^{\circ} \mathrm{C}\right)$ until use.

Cell culture and treatment. RAW264.7 cells were grown in monolayer culture using RPMI-1640 medium supplemented with $10 \%$ fetal bovine serum, 100 units $/ \mathrm{m} l$ of penicillin, and $100 \mu \mathrm{g} / \mathrm{m} l$ of streptomycin. Cell cultures were grown at $37^{\circ} \mathrm{C}$ in a humidified $\mathrm{CO}_{2}$ incubator $\left(5 \% \mathrm{CO}_{2}\right)$. The cells were passaged prior to confluence by removing cells with a trypsin solution, followed by centrifugation and reseeding. After 10 15 passages, RAW264.7 cells were no longer used for these assays. The effect of cytotoxicity was tested by treating cells with different concentrations of each extracted sample from Asterina pectinifera (60-MAP, 70MAP, 80-MAP, 90-MAP, He-AP, EA-AP and W-AP) in RPMI-1640 medium.

Cytotoxicity by MTT assay. The number of viable cells determined by the ability of mitochondria to convert MTT (3(4,5-dimethylthiazol-2-yl)-2,5-diphenyltetrazolium bromide) to formazan dye. RAW264.7 cells were cultured overnight in 96 -well plates, at a density of $3 \times 10^{4}$ cells $/ 200 \mu l$ in each well. The next day, the cells were coincubated with different concentrations of each extracted sample from Asterina pectinifera (60-MAP, 70-MAP, 80-MAP, 90-MAP, He-AP, EA-AP and W-AP) for $24 \mathrm{~h}$. After incubation, the medium was removed, with $10 \mu l$ of $10 \mathrm{mg} / \mathrm{ml}$ MTT then added to each well, and incubated for a further $4 \mathrm{~h}$, at $37^{\circ} \mathrm{C}$ in a humidified 5\% $\mathrm{CO}_{2}$ atmosphere. The MTT was removed, and cells lysed with $150 \mu l$ DMSO. The absorbance was measured at $550 \mathrm{~nm}$ using a microplate reader (OpsysMR, DYNEX. Ltd).

NO assay. The nitrite that accumulated in the culture medium was measured as an indicator of NO production based on the Griess reaction. In brief, RAW 264.7 cells were plated at a density of $2 \times 10^{5}$ cells in a 24 -well plate with $1 \mathrm{~m} l$ of culture medium and incubated for $18 \mathrm{~h}$. They were then coincubated with different concentrations of each extracted sample from Asterina pectinifera (60-MAP, 70MAP, 80-MAP, 90-MAP, He-AP, EA-AP and W-AP) in $500 \mathrm{ng} / \mathrm{m} l$ LPS for $24 \mathrm{~h}$. After treatment and LPS induction, culture supernatant was collected for nitrite measurement, $100 \mu l$ of the spent medium was plated in 96 -well plate and an equal amount of Griess reagent $(0.1 \% \mathrm{~N}-1$ (naphthyl)ethylenediamine-diHCl and $1 \%$ sulfanilamide and $5 \% \mathrm{H}_{3} \mathrm{PO}_{4}$ ) was added. The plate was incubated for $10 \mathrm{~min}$, and the absorbance was measured at $550 \mathrm{~nm}$ using a microplate reader. The amount of NO was calculated using sodium nitrite standard curve.

Cytokines assays. The inhibitory effects of each extract from Asterina pectinifera on the production of TNF- $\alpha$, and IL-6 were measured by an enzyme-linked immunosorbent assay (ELISA) using culture supernatants collected from treated cells. RAW 264.7 cells were seeded in a 24 -well plate at a density of $2 \times 10^{5}$ cells with $1 \mathrm{ml}$ of culture medium and incubated for $18 \mathrm{~h}$ and coincubated with different concentrations of each extracted sample from Asterina pectinifera (60MAP, 70-MAP, 80-MAP, 90-MAP, He-AP, EA-AP and W$\mathrm{AP}$ ) in $500 \mathrm{ng} / \mathrm{m} l \mathrm{LPS}$ for $24 \mathrm{~h}$. Cell-free culture supernatants were collected and assayed, according to the ELISA kit (OptiEIA, BD science, USA) manufacturer's instruction to determine the amount of TNF- $\alpha$ and IL- 6 that had been released from the cell. Concentrations were determined for two wells in each sample and this experiment done in triplicate.

Statistical analysis of data. All values were expressed as mean \pm the standard deviation $( \pm \mathrm{SD})$. Statistical differences between the treatments and the control were evaluated by ANOVA (Dunnett's test) and Students-t tests. $P<$ 0.05 was considered to be significant $(* P<0.05)$.

\section{RESULTS}

Yields of the methanolic and aqueous extract from Asterina pectinifera. In the present work, the methanolic extracts (60-MAP, 70-MAP, 80-MAP and 90-MAP), the potential bioactive compound fraction (He-AP and EAAP) and aqueous extract (W-AP) obtained from of Asterina pectinifera were prepared by the extractive method. The extractive yield of all extracts was shown in Table 1. The extractive yield was considerably more in aqueous extract than in methanolic extract. The extractive yield in methanolic extracts (60-MAP, 70-MAP, 80-MAP and 90-MAP), ranged from $9.8 \%$ to $21.7 \%$ while the aqueous extract (WAP) was $9.1 \%$. The hexane fraction (He-AP) and the ethyl acetate fraction (EA-AP) were ranged from $1.34 \%$ to $2.16 \%$. Maximum extractive yield was the 80 -MAP $(21.7 \%)$ of methonolic extract, while minimum methanolic extractive yield was the He-AP (1.34\%) of hexane fraction. In this study we found that the methnolic extracts showed profoundly distinct anti inflammatory activity from the aqueous extract and especially 80-MAP and EA-AP exhibited the strongest effect. These results were presented that $80 \%$ methanol was the most appropriate solvent for extraction of bioactive compound from Asterina pectinifera in the aspect of the yield.

Table 1. Comparison of yields in each extract from Asterina pectinifera

\begin{tabular}{lr}
\hline \hline Extract & \multicolumn{1}{c}{ Yield (\%) } \\
\hline 60-MAP & $14.6 \pm 0.11$ \\
70-MAP & $18.4 \pm 0.15$ \\
80-MAP & $21.7 \pm 0.13$ \\
90-MAP & $9.8 \pm 0.03$ \\
W-AP & $9.1 \pm 0.02$ \\
He-AP & $1.34 \pm 0.01$ \\
EA-AP & $2.16 \pm 0.01$ \\
\hline
\end{tabular}


Cytotoxicity effect of the methanolic and aqueous extract from Asterina pectinifera. The tetrazolium dye colorimetric test (MTT test) is used to monitor cell growth indirectly, as indicated by the conversion of the tetrazolium salt to the colored product, formazan, the concentration of which can be measured spectrophotometrically (Jung et al., 2004). In order to determine whether the methanolic and aqueous extract from Asterina pectinifera causes toxicity on RAW 264.7 cells, the cell viability was tested at various concentrations of each extracted sample from Asterina pectinifera (60-MAP, 70-MAP, 80-MAP, 90-MAP, and W-AP) in the cells by MTT assay. These results presented that the methanolic extracts of Asterina pectinifera showed averages $27 \%$ cell viability at high concentration $(2,000 \mu \mathrm{g} / \mathrm{m} l)$ and $\mathrm{IC}_{50}$ of these extracts was about $250 \mu \mathrm{g} / \mathrm{m} l$. Indeed, all the methanolic extracts (60-MAP, 70-MAP, 80-MAP and 90-MAP) induced a strong cytotoxicity at high concentra-
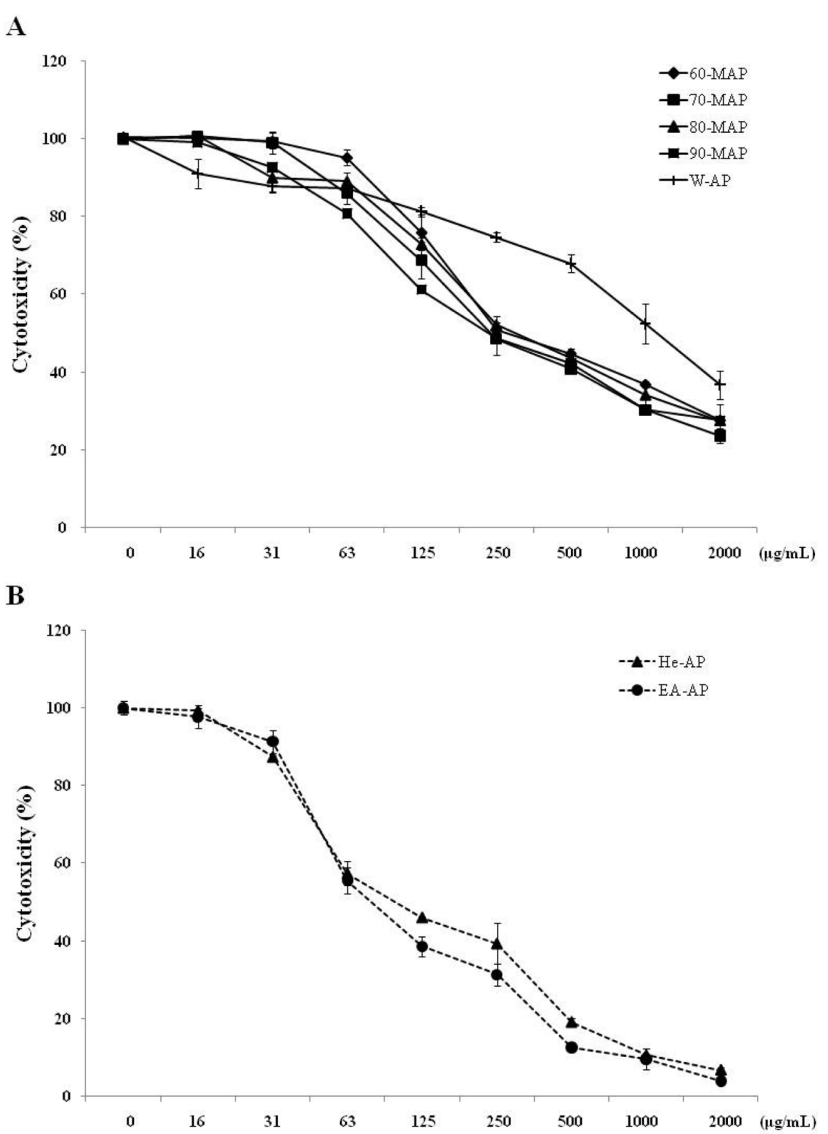

Fig. 2. Cytotoxicity of extracts from Asterina pectinifera in RAW 264.7 cell. RAW 264.7 cells were treated with each concentration of the methnolic extracts (60-MAP, 70-MAP, 80-MAP, and 90-MAP) and aqueous extract (W-AP) from Asterina pectinifera (A), hexane fraction (He-AP) and ethyl acetate fraction (EA-AP) (B) for $24 \mathrm{~h}$. Cell viability was determined by MTT assay. Three independent assays were performed in triplicate and the data shown are the mean \pm SD. tion (above $500 \mu \mathrm{g} / \mathrm{ml}$ ), but little cytotoxic effect at concentrations from 16 to $125 \mu \mathrm{g} / \mathrm{m} l$ on RAW 264.7 cells (Fig. 2A). On the other hand, the aqueous extract (W-AP) of Asterina pectinifera showed $57 \%$ cell viability at $1,000 \mu \mathrm{g} / \mathrm{m} l$ and $\mathrm{IC}_{50}$ of $\mathrm{W}$-AP was $1,000 \mu \mathrm{g} / \mathrm{ml}$ (Fig. 2B). Our data showed the methanolic extracts induced more cell cytotoxicity than the aqueous extract (W-AP). Therefore, in this study, we tested anti-inflammatory property below $\mathrm{IC}_{50}$ of all extracts (Fig. 2).

Inhibition of nitric oxide (NO) production by the methanolic and aqueous extract from Asterina pectinifera in LPS-stimulated RAW264.7 cells. We initially examined the inhibitory effects of the methanolic or aqueous extract from Asterina pectinifera on the production of the inflam-

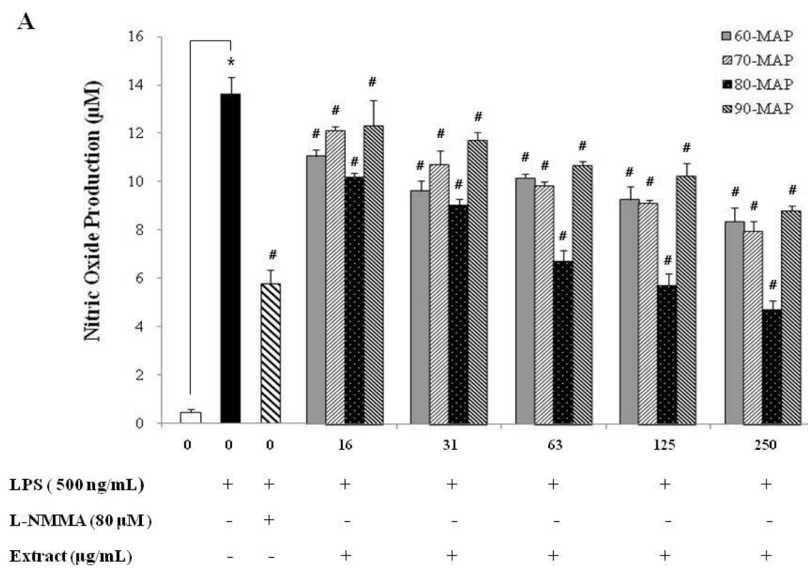

B

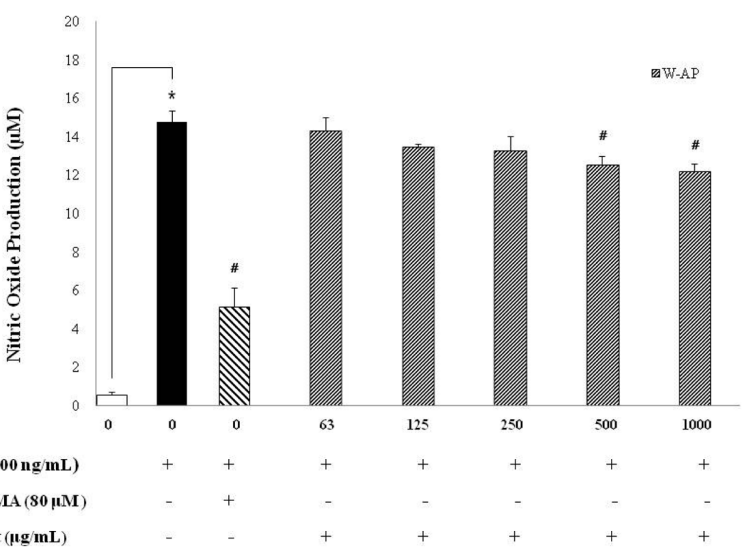

Fig. 3. Effects of the methanolic and aqueous extract from Asterina pectinifera on LPS-induced nitirc oxide (NO) in murine macrophages. RAW 264.7 cells were treated with concentrations of methanolic and aqueous extract from Asterina pectinifera (60-MAP, 70-MAP, 80-MAP, 90-MAP, and W-AP) in the presence of $500 \mathrm{ng} / \mathrm{m} /$ of LPS or LPS alone for $24 \mathrm{~h}$. L-NMMA was used as a positive control. Three independent assays were performed in triplicate and the data shown are the mean \pm S.D. ${ }^{*} P<0.05$ vs. media alone and ${ }^{\#} P<0.05$ vs. LPS-treated group (control); significance of difference between treated groups by Students-t tests ( $\left(^{*}\right)$ and ANOVA followed by Dunnett's test ( $\left(^{*}\right)$. 
matory mediators, nitric oxide (NO). Here, it has been demonstrated that Asterina pectinifera significantly inhibited NO productions in LPS-stimulated RAW 264.7 cells according to extract method. The amount of produced NO was indicated by amount of nitrite (a stable metabolite of NO) that accumulated in LPS-exposed cells in the presence of each type of these extracts. The methanolic extracts (60-MAP, 70-MAP, 80-MAP and 90-MAP) of Asterina pectinifera significantly inhibited LPS induced NO production (Fig. 3A). Especially, 80 -MAP by extracted $80 \%$ methanol was decreased the strongest NO production among the methanolic extracts. Although the other methanolic extracts (60MAP, 70-MAP, and 90-MAP) also had an inhibitory effect on NO production, the effect was not as strong as that exhibited by 80 -MAP (Fig. 3A). The methanolic extracts also significantly inhibited LPS-induced NO production in a dose-dependent manner $(P<0.05)$. Unstimulated cells secreted basal levels of NO $(0.01 \mu \mathrm{M})$, while LPS stimulation resulted in an increase in NO production $(14 \pm 0.66 \mu \mathrm{M}$; inhibition 0\%) (Fig. 3A). In addition to, 80-MAP had strongly inhibitory effect on NO production the same as that exhibited L-MMNA $(6 \pm 0.6 \mu \mathrm{M}$; inhibition $59 \%)$ as NO synthase inhibition. Meanwhile, the aqueous extract (WAP) of Asterina pectinifera suppressed significantly NO production in a dose-dependent manner $(P<0.05)$ but this was lower than methanolic extracts (Fig. 3B). Indeed, 80-MAP among the methanolic or aqueous extracts showed a strong inhibition of NO production the same as positive control.

Reduced production of pro-inflammatory cytokines by the methanolic and aqueous extract from Asterina pectinifera in LPS stimulated RAW264.7 cells. To examine the inhibition effect of these extracts on the production of the pro-inflammatory cytokines, TNF- $\alpha$ and IL-6, RAW264.7 cells were incubated with various concentrations of each extract in the presence of LPS for $24 \mathrm{~h}$. As shown in Fig. 4, LPS induced TNF- $\alpha$ secretion was reduced by the methanolic extracts (60-MAP, 70-MAP, 80-MAP and 90-MAP) of Asterina pectinifera. Just like NO production, 80-MAP inhibited more TNF- $\alpha$ secretion than the other methanolic extracts (60-MAP, 70-MAP, and 90-MAP). Thus our data presented that 80-MAP significantly inhibited LPS stimulated TNF- $\alpha$ secretion in a concentration-dependent manner $(P<0.05)$. We also found that treatment with the methanolic or aqueous extract the same as TNF- $\alpha$ secretion could inhibit IL-6 secretion as compared with the untreated control in LPS-stimulated RAW 264.7 cells (Fig. 5). Then 80-MAP induced reduction of TNF- $\alpha$ as well as IL- 6 secretion and significantly reduced secretion of pro-inflammatory cytokines in a concentration-dependent manner $(P<$ $0.05)$. Treatment of polymixn B $(100 \mathrm{U} / \mathrm{m} l)$ as LPS inhibitor was significantly reduced $10 \mathrm{ng} / \mathrm{m} l$ in TNF- $\alpha$ and $3 \mathrm{ng} /$ $\mathrm{m} l$ in IL-6 secretion as compared as LPS alone $(27 \mathrm{ng} / \mathrm{m} l$ in TNF- $\alpha$ and $10 \mathrm{ng} / \mathrm{m} l$ in IL-6) $(P<0.05)$. The aqueous

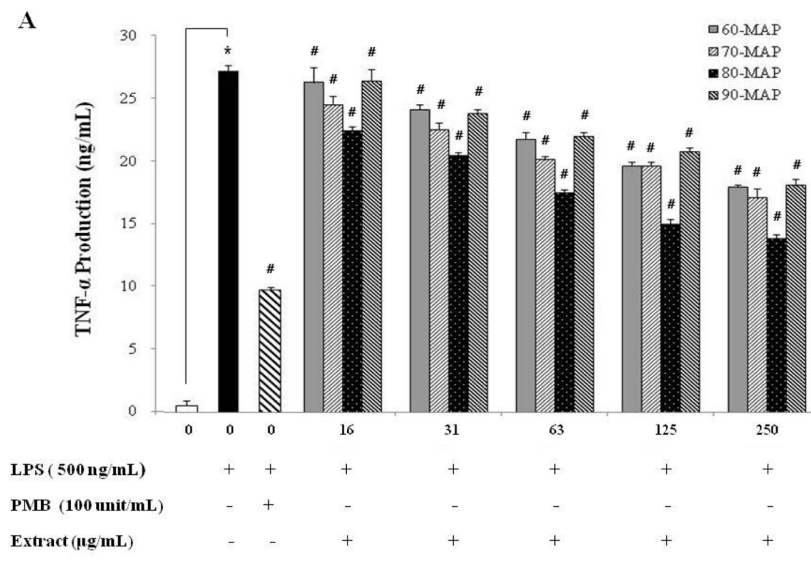

B

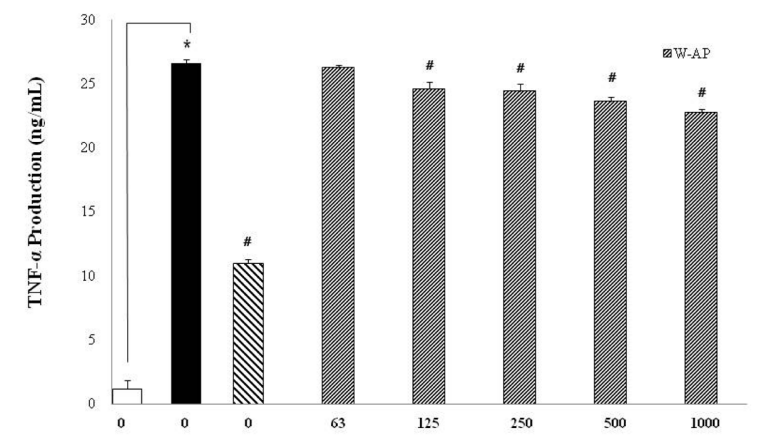

LPS ( $500 \mathrm{ng} / \mathrm{mL})$

PMB $(100$ unit/mL)

Extract $(\mathbf{n g} / \mathbf{m L})$

Fig. 4. Effects of the the methanolic and aqueous extract from Asterina pectinifera on LPS-induced TNF- $\alpha$ production by RAW 264.7 cells. Cells were treated with the indicated concentrations of methanolic and aqueous extract from Asterina pectinifera (60MAP, 70-MAP, 80-MAP, 90-MAP, and W-AP) in the presence of $500 \mathrm{ng} / \mathrm{m} /$ of LPS or LPS alone for $24 \mathrm{~h}$. The concentration of TNF- $\alpha$ in condition medium was analyzed by ELISA. Three independent assays were performed in triplicate and the data shown are the mean \pm S.D. ${ }^{*} P<0.05$ vs. media alone and ${ }^{\#} P<0.05$ vs. LPS-treated group (control); significance of difference between treated groups by Students-t tests $\left(^{*}\right)$ and ANOVA followed by Dunnett's test $\left({ }^{\#}\right)$.

extract (W-AP) of Asterina pectinifera also significantly inhibit production of pro-inflammatory cytokine such as TNF- $\alpha$ and IL- 6 in a concentration-dependent manner $(P<$ $0.05)$ but this was lower than methanolic extracts alike NO production (Fig. 4B \& Fig. 5B). These results indicated that 80-MAP among the methanolic extracts reduced of production of pro-inflammatory cytokine in a concentration-dependent manner. Together, our results strongly suggested that 80-MAP among these extracts exerted in vitro anti-inflammatory activity in LPS-stimulated RAW264.7 cells.

Anti inflammatory effect by bioactive fraction from 80-MAP of Asterina pectinifera. We performed to extractive method to the next grade active fraction, which 
A
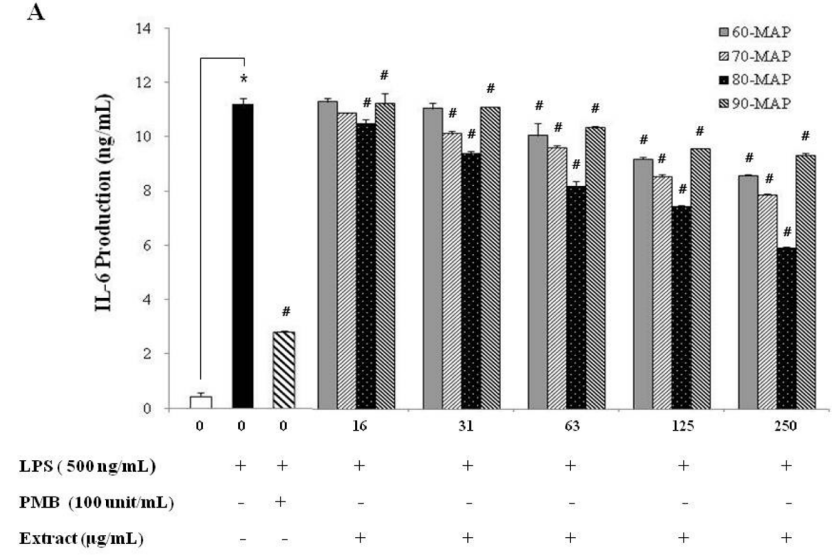

B

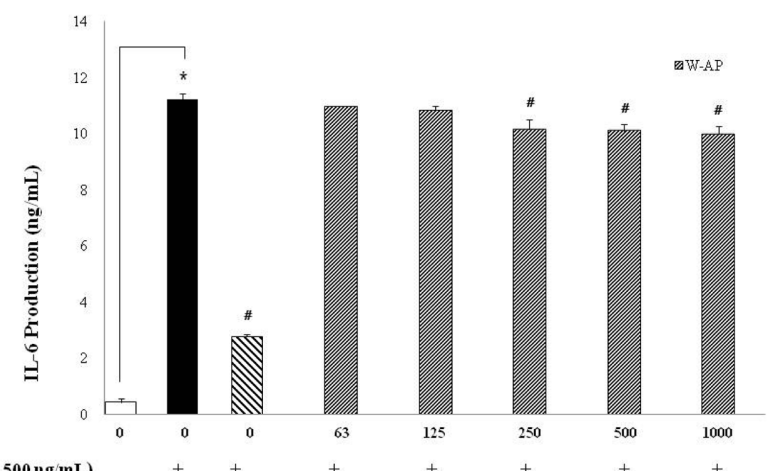

PMB (100 unit/mL)

Extract $(\boldsymbol{\mu g} / \mathbf{m L})$

Fig. 5. Effects of the methanolic and aqueous extract from Asterina pectinifera on LPS-induced IL-6 production by RAW 264.7 cells. Cells were treated with the indicated concentrations of methanolic and aqueous extract from Asterina pectinifera (60MAP, 70-MAP, 80-MAP, 90-MAP, and W-AP) in the presence of $500 \mathrm{ng} / \mathrm{m} /$ of LPS or LPS alone for $24 \mathrm{~h}$. The concentration of IL6 in condition medium was analyzed by ELISA. Three independent assays were performed in triplicate and the data shown are the mean \pm S.D. ${ }^{*} P<0.05$ vs. media alone and ${ }^{\#} P<0.05$ vs. LPS-treated group (control); significance of difference between treated groups by Students-t tests $\left(^{*}\right)$ and ANOVA followed by Dunnett's test $(*)$

contained potential bioactive compounds, from 80-MAP of Asterina pectinifera. The hexane fraction (He-AP) was extracted from 80-MAP using $80 \%$ methanol and the ethyl acetate fraction (EA-AP) were extracted from the other methnolic layer except He-AP (Fig. 1). In the Fig. 2B, the $\mathrm{He}-\mathrm{AP}$ and EA-AP induced a strong cytotoxicity from $500 \mu \mathrm{g} /$ $\mathrm{m} l$ to $2,000 \mu \mathrm{g} / \mathrm{m} l$ and $\mathrm{IC}_{50}$ of these fractions was about $63 \mu \mathrm{g} / \mathrm{ml}$ (Fig. 5A). To determine whether the He-AP or EA-AP inhibit NO production, we tested the murine macrophage cell line, RAW264.7, for $24 \mathrm{~h}$ with various concentrations of these fractions. Consistent with the findings shown in Fig. 6A, the He-AP or EA-AP was responsible for an significantly inhibitory effect on NO production in dose
A

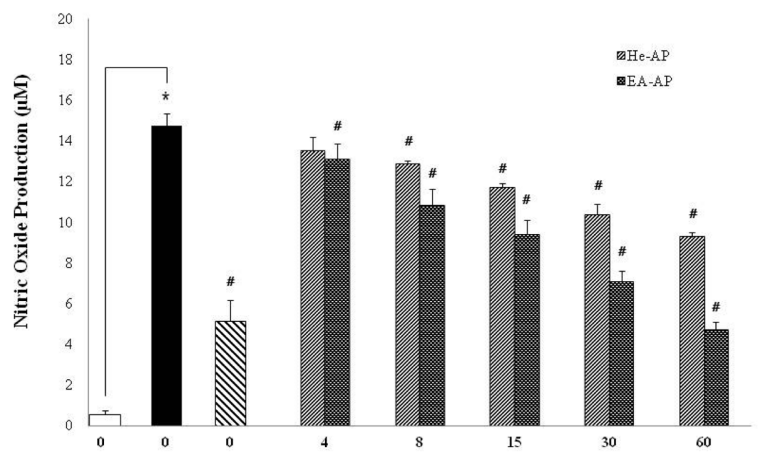

$\operatorname{LPS}(500 \mathrm{ng} / \mathrm{mL})$

L-NMMA (80 بM)

Fraction $(\mu \mathrm{g} / \mathbf{m L})$

B

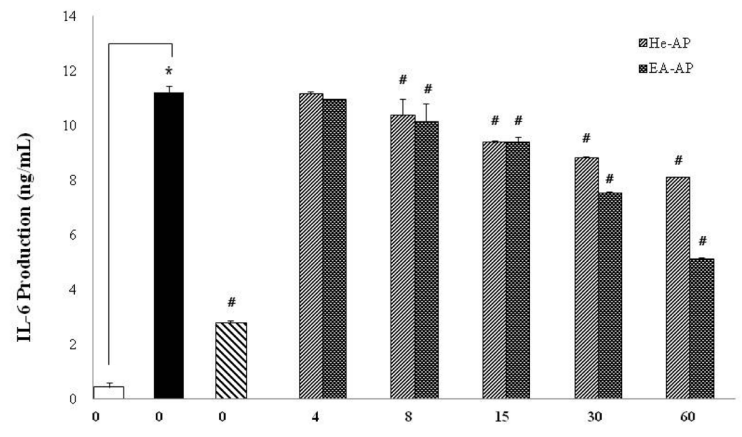

LPS $(500 \mathrm{ng} / \mathrm{mL})$

PMB (100 unit/mL)

Fraction $(\boldsymbol{n g} / \mathbf{m L})$

C

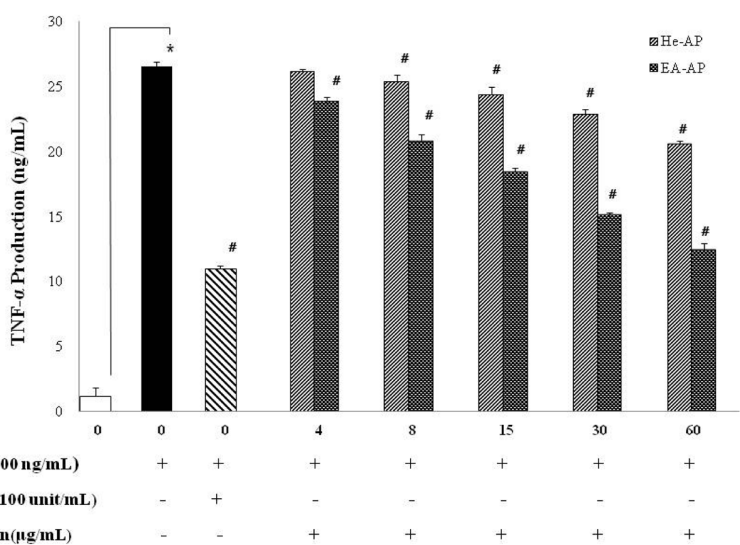

Fig. 6. Effects by active compound fraction from 80-MAP of Asterina pectinifera on LPS-induced nitirc oxide (NO), IL-6 production and TNF- $\alpha$ production in murine macrophages. RAW 264.7 cells were treated with concentrations of hexane fraction (He-AP) and ethyl acetate fraction (EA-AP) in the presence of $500 \mathrm{ng} / \mathrm{m} /$ of LPS or LPS alone for $24 \mathrm{~h}$. The production of NO was evaluated by Griess reaction (A). The concentration of IL- 6 (B) and TNF- $\alpha$ (C) in condition medium was analyzed by ELISA. Three independent assays were performed in triplicate and the data shown are the mean \pm S.D. ${ }^{*} P<0.05$ vs. media alone and ${ }^{\#} P<0.05$ vs. LPS-treated group (control); significance of difference between treated groups by Students-t tests $\left(^{*}\right)$ and ANOVA followed by Dunnett's test ( ${ }^{\#)}$. 
dependent $(P<0.05)$ but the EA-AP exerted anti inflammatory activity more than the He-AP in NO inhibition. We next investigated the effect of the He-AP or EA-AP on proinflammatory cytokine production. IL-6 and TNF- $\alpha$ level in the culture supernatants were evaluated using ELISA. TNF$\alpha$ and IL-6 levels had significantly increased from RAW 264.7 cells in response to LPS stimulation alone (Fig. 6B \& 6C). LPS induced TNF- $\alpha$ secretion by the He-AP or EAAP was measured at $21 \pm 0.27 \mathrm{ng} / \mathrm{m} l$ and $12 \pm 0.53 \mathrm{ng} / \mathrm{m} l$ at the high concentration $(60 \mu \mathrm{g} / \mathrm{m} l)$, respectively. Each of them also secreted at $8 \pm 0.02 \mathrm{ng} / \mathrm{m} l$ and $5 \pm 0.06 \mathrm{ng} / \mathrm{m} l$ at $60 \mu \mathrm{g} / \mathrm{m} l$ in IL-6 secretion. In addition to, the both He-AP and EA-AP was significantly inhibited on NO, TNF- $\alpha$ and IL-6 production in a concentration-dependent manner $(P<$ 0.05 ), however the EA-AP showed stronger anti inflammatory activity than the He-AP in inflammatory mediators. These findings suggested that the EA-AP might be contained a potential bioactive compound in anti inflammatory agent.

\section{DISCUSSION}

Marine organism inferring about 30 phylum, 500 thousand species, which corresponds to about 85 percent of the living organism on the earth (Cundliffe, 1981). Especially, marine organism might have unique self-defensive ability to survive in competition because marine is consisted with special ecosystem different from a land. Therefore, a studies for the search of new bioactive compounds from marine organism has been actively doing, and such a possibility is unlimited if variety of marine organisms is considered (Ruggieri, 1976). A very large number of secondary metabolites as natural products produced by marine organisms have been identified. These secondary metabolites as natural products include some of the most potent inhibitors of cellular metabolic reactions (Choi, 1993; Seo, 1997). Due to the pharmacological actions some of the biologically active natural products have become excellent sources of new and effective drugs such on antifungal, anti-inflammatory and antiviral agents.

In this study, we utilized murine macrophage, RAW 264.7 cells as a model to test the anti-inflammatory capacity of each extract from starfish, Asterina pectinifera according to extract method. It was obvious that the methanolic extract of Asterina pectinifera had a more efficient ability to restrain the secretion of nitric oxide (NO), TNF- $\alpha$ and IL-6 at a dosedependent manner in LPS-stimulated cells (Fig. 3 Fig. 5).

NO synthesized by the enzyme inducible nitric oxide synthesis (iNOS) has been reported as a mediator of inflammation and seems to be involved in both acute and chronic inflammation (De las Heras et al., 2001). The physiological or normal generation of NO mediates the bactericidal and tumoricidal actions of macrophages. However, the aberrant release of NO can lead to amplification of inflammation, as well as tissue injury (Evans, 1995). Large amounts of pro- inflammatory mediators, nitric oxide (NO), and prostaglandin E2 (PGE2) are generated by the inducible isoforms of NO synthase (iNOS) and COX-2 (Vane et al., 1994). The increased production of these inflammatory mediators may result in severe tissue damage and septic shock. Nitric oxide (NO) is a signaling molecule that plays a key role in the pathogenesis of inflammation. Furthermore, pro-inflammatory cytokines such as TNF- $\alpha$, IL- $1 \beta$ and IL- 6 have been shown to control inflammation in vitro as well as in vivo and these cytokines are thought to be interlinked in a cascade, being produced serially by macrophages during an inflammatory response (Feldmann et al., 1996). These cytokines appear to be interlinked in a cascade, being produced serially by cells during an inflammatory response. Inhibition of NO and pro-inflammatory cytokines production is a very important therapeutic target point in the development of anti-inflammatory agents. Indeed, RAW 264.7 macrophages provide us with an excellent model for anti-inflammatory drug screening to the production of pro-inflammatory cytokines (Abreu, 2004). Therefore, because the overproduction of NO and pro-inflammatory cytokines can be harmful and result in various inflammatory and autoimmune diseases (Tergaonkar, 2006) pharmacological interference with the inflammatory mediator production cascade presents a promising strategy for natural sources to cure inflammatory disorders.

Hence, in the present work, methanol and enzyme (Prota$\mathrm{mex}^{\mathrm{TM}}$ ) were used for the extraction. The extractive yield of all the extract is shown in Table 1. The extractive yield was considerably more in the methanolic extract than in aqueous extract with protease. Especially the 80-MAP among methonolic extracts showed the highest yields, about $21.7 \%$, and next was the 70-MAP at $18.4 \%, 60-\mathrm{MAP}$ at $14.6 \%, 90-$ MAP at $9.8 \%$, W-AP at $9.1 \%$, EA-AP at $2.16 \%$ and the HeAP of hexane fraction was the lowest at $1.34 \%$. Therefore, $80 \%$ methanol was the most effective solvent for extraction of anti inflammatory substances from Asterina pectinifera in the aspect of the yield. We also determined whether these extracts from Asterina pectinifera induced cell cytoxicity and the cell viability was tested at various concentrations of each extracted sample from Asterina pectinifera (60-MAP, 70-MAP, 80-MAP, 90-MAP, and W-AP) in the on RAW 264.7 cells. As shown Fig. 2, all the methanolic extracts (60-MAP, 70-MAP, 80-MAP and 90-MAP) induced a strong cytotoxicity (averages $27 \%$ cell viability) at high concentration (above $500 \mu \mathrm{g} / \mathrm{m} l$ ) but the aqueous extract (W-AP) showed $74 \%$ cell viability at the same concentration on RAW 264.7 cells. These results suggested that the methanolic extracts induced more cytotoxicity than the aqueous extract.

We found that the methanolic extracts (60-MAP, 70-MAP, 80-MAP and 90-MAP) from Asterina pectinifera dramatically inhibited LPS-induced NO production in a dose-dependent manner $(P<0.05)$. (Fig. 3) but the aqueous extract (W-AP) had a weakly inhibitory effect. In particular, the 
80-MAP among all extracts of Asterina pectinifera showed a strong inhibition of NO production. In addition to, the methanolic or aqueous extract from Asterina pectinifera in LPS-stimulated RAW 264.7 cells also suppressed secretion of pro-inflammatory cytokines (Fig. 4 \& Fig. 5). Consistent with the findings shown in NO production, IL-6 and TNF-á secretion was reduced by the methanolic extracts (60-MAP, 70-MAP, 80-MAP and 90-MAP) and 80-MAP inhibited more IL- 6 and TNF- $\alpha$ secretion more than the other methanolic extracts in a concentration-dependent manner $(P<$ 0.05 ) (Fig. 5). Indeed, we tested clear anti-inflammatory potential for screening of the active fraction, which contained potential bioactive compounds, and these fractions extracted from 80-MAP of Asterina pectinifera between of the hexane fraction (He-AP) and the ethyl acetate fraction (EA-AP) (Fig. 1). As shown Fig. 6, the He-AP or EA-AP was responsible for an significantly inhibitory effect on inflammatory mediators such as NO, IL-6 and TNF- $\alpha$ secretion in dose dependent $(P<0.05)$ however the EA-AP exerted anti-inflammatory activity more than the He-AP in NO inhibition. In this study, these results suggested that extracted the EA-AP from the $80 \%$ methanolic extract (80MAP) of Asterina pectinifera might have potential bioactive compound to contribute anti-inflammatory activity.

Many other natural products isolated from marine organisms like starfish have been little known to exert inhibitory effects on a variety of inflammation and thus may serve as models for the synthesis of new drugs. Our findings suggest that the EA-AP might imply the existence of effective anti inflammatory compounds and might be a good candidate for development into a product designed to prevent inflammatory disease. Although the active compound(s) responsible for the anti-inflammatory effects of the EA-AP are still unknown, experimental evidence from our study suggested that they could be found in the ethyl acetate fraction (EA-AP) of Asterina pectinifera. Furthermore, such activity appears to be mediated through the ability of these compounds to reduce the rate of production of the inflammatory mediators NO, and the pro-inflammatory cytokines. We will further undertake isolation and structural elucidation of functional compounds, the establishment of safety of functional compounds and the mechanism of anti-inflammatory activity by functional compounds in the next experiment. Indeed, it might be considered that our data could be suggest the basic result for the further study of availability of bioactive compounds as anti-inflammatory agent from isolated natural source of marine organisms, and could reduce damage of coastal shellfish farm, and also could utilize as a new income of fisherman by efficient usages of unused marine resources.

\section{ACKNOWLEDGMENTS}

This research was supported by Dong-A University.

\section{REFERENCES}

Abreu, M.T. and Arditi, M. (2004). Innate immunity and toll-like receptors: clinical implications of basic science research. $J$. Pediatr., 144, 421-429.

Albert, D., Zündorf, I., Dingermann, T., Müller, W.E., Steinhilber, D. and Werz, O. (2002). Hyperforin is a dual inhibitor of cyclooxygenase-1 and 5-lipoxygenase. Biochem. Pharmacol., 64, 1767-1775.

Boscá, L., Zeini, M., Través, P.G. and Hortelano, S. (2005). Nitric oxide and cell viability in inflammatory cells: a role for NO in macrophage function and fate. Toxicology, 208, 249-258.

Cho, S.Y., You, B.J., Chang, M.H., Lee, S.J., Sung, N.J. and Lee, E.H. (1994). Screening for antimicrobial compounds in unused marine resources by the paper disk method. Kroean J. Food Sci. Technol., 26, 261-165.

Cho, S.Y., Kang, H.J., Joo, D.S., Jeon, J.K., Oh, M.H. and Kim, J.S. (2000). Seperation and identification of nature antimicrobial agent from starfish. Paper presented at 47th Conference of Korean Soc. Food Sci. Nutr., Kangwon National University, Kangwon.

Cho, S.Y., Kang, H.J., Joo, D.S., Jeon, J.K., Kim, O.S. and Kim, J.S (2000). Seperation and identification of nature antioxidative agent from starfish and sea urchin integument. Paper presented at $47^{\text {th }}$ Conference of Korean Soc. Food Sci. Nutr., Kangwon National University, Kangwon.

Cho, S.Y., Kang, H.J., Joo, D.S., Jeon, J.K., Cho, J.S., Lee, C.H. and Kim, J.S (2000). Seperation and identification of nature anticholestrol agent from starfish, sea urchin integument and sea squirt integument. Paper presented at 47 th Conference of Korean Soc. Food Sci. Nutr., Kangwon National University, Kangwon.

Cho, S.Y., Kang, H.J., Joo, D.S., Jeon, J.K., Kim, J.S. and Lee, Y.S. (2000). Seperation and identification of nature anticoagulant agent from starfish, sea urchin integument and sea squirt integument. Paper presented at 47th Conference of Korean Soc. Food Sci. Nutr., Kangwon National University, Kangwon.

Choi, D.H. (1993). Studies on the screening and chemical properties of antifungal compound from Asternia sp., Dongguk University.

Choi, D.H., Shin, S. and Park, I.K. (1999). Characterization of antimicrobial agents extracted from Asterina pectinifera. Int. J. Antimicrob. Agents, 11, 65-68.

Coker, R.K. and Laurent, G.J. (1998). Pulmonary fibrosis: cytokines in the balance. Eur. Resp. J., 11, 1218-1221.

Cundliffe, E. (1981). Antibiotic inhibitors of ribosome function. In: Gale EF, editor. The Molecular Basis of Action. 2nd ed. Chichester, UK: Wiley.

de las Heras, B., Abad, M.J., Silván, A.M., Pascual, R., Bermejo, P., Rodríguez, B. and Villar, A.M. (2001). Effects of six diterpenes on macrophage eicosanoid biosynthesis. Life Sci., 70, 269278.

Evans, C.H. (1995). Nitric oxide: what role does it play in inflammation and tissue destruction?. Agents Actions Suppl., 47, 107116.

Kang, H.J. (2000). The development of useful bioactive compounds from marine organisms, Kangnung National University.

Feldmann, M., Brennan, F.M. and Maini, R.N. (1996). Rheumatoid arthritis. Cell, 85, 307-310. 
Fichtner-Feigl, S., Fuss, I.J., Preiss, J.C., Strober, W. and Kitani, A. (2005). Treatment of murine Th1- and Th2-mediated inflammatory bowel disease with NF-kappa B decoy oligonucleotides. J. Clin. Invest., 115, 3057-3071.

Ishiguro, Y. (1999). Mucosal proinflammatory cytokine production correlates with endoscopic activity of ulcerative colitis. $J$. Gastroenterol., 34, 66-74.

Jung, H.A., Chung, H.Y., Yokozawa, T., Kim, Y.C., Hyun, S.K. and Choi, J.S. (2004). Alaternin and emodin with hydroxyl radical inhibitory and/or scavenging activities and hepatoprotective activity on tacrine-induced cytotoxicity in HepG2 cells. Arch. Pharm. Res., 27, 947-953.

Klotz, L., Schmidt, M., Giese, T., Sastre, M., Knolle, P., Klockgether, T. and Heneka, M.T. (2005). Proinflammatory stimulation and pioglitazone treatment regulate peroxisome proliferatoractivated receptor gamma levels in peripheral blood mononuclear cells from healthy controls and multiple sclerosis patients. J. Immunol., 175, 4948-4955.

Park, M.S. and Kim, B.Y. (1985). Feeding behaviour of the starfish, Asterias amurensis (LUTKEN). Bull. Fish. Res. Dev. Agency., 34, 1-174.

Park, S.W., Kim, T.H. and Oh, H.K. (1997). A study on the development of the extermination gear for starfish, Asterias amurensis and its efficiency. Bull. Korean Soc. Tech., 33, 166-172.

Prendergast, R.A. and Suzuki, M. (1970). Invertebrate protein simulating mediators of delayed hypersensitivity. Nature, 227, 277279.

Prokof'eva, N.G., Chaikina, E.L., Kicha, A.A. and Ivanchina, N.V. (2003). Biological activities of steroid glycosides from starfish. Comp. Biochem. Physiol. B. Biochem. Mol. Biol., 134, 695-701.

Penglis, P.S., Cleland, L.G., Demasi, M., Caughey, G.E. and James, M.J. (2000). Differential regulation of prostaglandin E2 and thromboxane A2 production in human monocytes: implications for the use of cyclooxygenase inhibitors. J. Immunol., 165, 1605-1611.

Ruggieri, G.D. (1976). Drugs from the sea. Science, 194, 491-497.
Sakagami, T., Vella, J., Dixon, M.F., O'Rourke, J., Radcliff, F., Sutton, P., Shimoyama, T., Beagley, K. and Lee, A. (1997). The endotoxin of Helicobacter pylori is a modulator of host-dependent gastritis. Infect. Immun., 65, 3310-3316.

Sautebin, L. (2000). Prostaglandins and nitric oxide as molecular targets for anti-inflammatory therapy. Fitoterapia, 71, S48-S57.

Seo, J.K. (1997). Conformation and biological activity of Mastoparan B and its analogs: Isolation and charcterization of the biological substances from Inshore Hagfish (Eptatretus burgeri) skin and starfish (Asterina pectinifera). Pukyong National University.

Sobota, R., Szwed, M., Kasza, A., Bugno, M. and Kordula, T. (2000). Parthenolide inhibits activation of signal transducers and activators of transcription (STATs) induced by cytokines of the IL-6 family. Biochem. Biophys. Res. Commun., 267, 329333.

Sosa, S., Balick, M.J., Arvigo, R., Esposito, R.G., Pizza, C., Altinier, G. and Tubaro, A. (2002). Screening of the topical antiinflammatory activity of some Central American plants. J. Ethnopharmacol., 81, 211-215.

Tergaonkar, V. (2006). NFkappaB pathway: a good signaling paradigm and therapeutic target. Int. J. Biochem. Cell Biol., 38, 1647-1653.

Vane, J.R., Mitchell, J.A., Appleton, I., Tomlinson, A., BishopBailey, D., Croxtall, J., Willoughby, D.A. (1994). Inducible isoforms of cyclooxygenase and nitric-oxide synthase in inflammation. Proc. Natl. Acad. Sci., 91, 2046-2050.

Vernooy, J.H., Dentener, M.A., van Suylen, R.J., Buurman, W.A. and Wouters, E.F. (2002). Long-term intratracheal lipopolysaccharide exposure in mice results in chronic lung inflammation and persistent pathology. Am. J. Respir. Cell. Mol. Biol., 26, 152-159.

Walsh, N.C., Crotti, T.N., Goldring, S.R. and Gravallese, E.M. (2005) Rheumatic diseases, the effects of inflammation on bone. Immuno. Rev., 208, 228-251. 